\title{
Bibliotecas, usuários e tecnologias info-comunicacionais: perspectivas e transformações
}

\author{
Walqueline Silva Araújo \\ walqueline.araujo@gmail.com \\ Universidade Federal da Paraíba \\ José Mauro Matheus Loureiro \\ immloureiro@gmail.com \\ Universidade Federal do Rio de Janeiro \\ Gustavo Henrique Araújo Freire \\ ghafreire@gmail.com \\ Universidade Federal da Paraíba
}

Resumo: Este artigo objetiva refletir sobre as transformações sociais e culturais do processo de consolidação da cibercultura, decorrentes da inserção e popularização das Tecnologias Digitais de Informação e Comunicação na sociedade, bem como as contribuições dessas tecnologias como canal mediador para a troca de informações entre as bibliotecas e seu público-alvo. A reflexão busca ponderar sobre as perspectivas e transformações nas formas de se relacionar que ferramentas como as mídias sociais têm possibilitado por meio da internet, buscando destacar aspectos essenciais que envolvem a biblioteca universitária e o usuário da informação. Utiliza como instrumento de pesquisa uma revisão bibliográfica, sendo realizada uma pesquisa bibliográfica e documental em fontes como livros e periódicos científicos eletrônicos de leitura corrente, com vistas a apresentar os conceitos e definições do tema abordado. Consideramos que é necessário que o profissional da informação inove, trazendo para a biblioteca novas formas de se relacionar com o usuário, modernize e incorpore alterações que atendam ao atual cenário de cultura virtual que se consolida cada vez mais em nossa sociedade, frutos das transformações provenientes da contemporaneidade.

Palavras-chave: tecnologias digitais de informação e comunicação; usuário da informação; bibliotecas universitárias; cibercultura.

\begin{abstract}
It aims at reflecting upon cultural and social transformations within the cyberculture consolidation process, which are the result of the insertion and the popularization, in society, of the Information and Communication Digital Technologies, as well as upon such technologies' input as the mediator channel for information exchange among libraries and their public. The reflection searches for focusing on both perspectives and transformations as to ways in managing which tools - such as the social media - have made the mentioned transformations possible through the Internet, seeking to highlight essential aspects that refer to the university library and to the information user. As related to the research's tool, it develops a bibliographical review, by means of a bibliographical and documentary survey in sources like books and updated reading electronic scientific periodicals, so as to present concepts and definitions of the approached issue. We consider that it is necessary for the information professional to improve himself/herself, by bringing to the library new ways of dealing with the user. Furthermore, he/she needs to update his/her professional background, including changes that respond to the present scenery of the virtual culture, which is even more consolidated in our society - the outcome of transformations that are arisen from contemporaneity.
\end{abstract}

Keywords: information and communication digital technologies; information user; university library; cyberculture. 


\section{INTRODUÇÃO}

Torna-se cada vez mais notável as transformações que vem ocorrendo no cenário do trabalho informacional. Os últimos anos mostram um crescimento e uma valorização da informação imediata e de fácil acesso, seja no contexto das organizações que necessitam utilizar informações para otimizar os seus processos administrativos e de inteligência, seja também nas exigências informacionais que a sociedade contemporânea apresenta. Esse contexto é permeado pelas Tecnologias Digitais de Informação e Comunicação (TDICs), são dispositivos computacionais, como computadores, tablets, smartphones, entre outros, que funcionam como um canal que propicia, quando conectados à internet, o acesso à um volume muito grande de informações dos mais variados gêneros, que atende desde a busca para uma tomada de decisão, pesquisa acadêmica, previsão do tempo, até uma simples pesquisa de matérias para entretenimento. $O$ acesso fácil à essas tecnologias vem modificando não só questões comportamentais, como também culturais, sociais e econômicas. Lemos (2007) nos assevera que "a cultura contemporânea, associada às tecnologias digitais (ciberespaço, simulação, tempo real, processos de virtualização, etc.) vai criar uma nova relação entre a técnica e a vida social que chamaremos de "cibercultura". De acordo com Lévy (1999), a cibercultura é "um movimento social e cultural propagado pelo ciberespaço cada vez mais potente e vigoroso, e converge sobre uma forma de comunicação não midiática, interativa, comunitária, transversal e rizomática".

Nessa perspectiva em paralelo ao surgimento das TDICs e de sua otimização técnica no cenário da cibercultura temos a internet que é o símbolo que sobressai nesse nova conjuntura sociocultural, proporcionando o acesso à uma gama de informações de diversas áreas do saber, podendo ser: científicas, culturais, utilitárias, entre outras. A intensidade com a qual se apresenta a inserção da internet nos processos comunicacionais e informativos, leva-nos a refletir sobre as questões socioculturais dessas tecnologias, suas perspectivas e transformações no cotidiano dos usuários da informação. Essas transformações são percebidas principalmente através do uso de ferramentas que possibilitam a interação direta entre usuários e os sistemas de informação. Segundo Levy

A cibercultura emerge de uma forma de socialização, emanada da interação humana e mediada pelas TIC's e expressa a pretensão de construir um laço social dissociado dos links territoriais, das instituições e as relações de poder, mas a reunião em torno de centros de interesses comuns compartilhamento do saber, da aprendizagem cooperativa e dos processos abertos de colaboração (LÉVY, 1999).

Nesse contexto, Arruda (2011) escreve na perspectiva da existência de "um excesso de bits que homogeneíza e massifica as diversidades culturais, transforma o mundo 
em uma aldeia global, na qual todos estão conectados e interligados o tempo inteiro, independente da distância". Na sociedade em que a informação flui em grande velocidade e quantidade, a informação pode ser encontrada em diversos meios, nos mais diversos formatos, disponibilizadas virtualmente. Esses recursos informacionais estão à disposição das pessoas em versão eletrônica, como documentos multimídia, listas de discussão, fóruns eletrônicos, conferências, imagens fixas ou animadas, e em diversas bases de dados que retratam uma infinidade de informações.

A velocidade na atualização informacional na rede de certa forma se torna bem maior se comparado aos acervos das bibliotecas tradicionais, devido aos processos técnicos que uma obra impressa necessita antes de ser disponibilizada ao consumidor final, isso acaba contribuindo para uma migração por parte de alguns usuários na hora de escolher as fontes de pesquisas. $\mathrm{O}$ acesso adequado e atualizado às informações é essencial para o desenvolvimento da sociedade, pois, a informação, quando assimilada de forma correta produz conhecimento, agrega valor às informações já assimiladas pelo indivíduo e traz benefícios ao seu desenvolvimento e ao desenvolvimento da sociedade em que ele vive. Segundo Freire

$\mathrm{Na}$ sociedade contemporânea, as tecnologias digitais possibilitam aos usuários grande mobilidade na busca de informação em fontes remotas, como nunca visto, oferecendo-lhes a oportunidade de criar seus próprios espaços de produção e comunicação de informação. [...] A Internet é um espaço comunicacional que permite, a partir do cumprimento de certos procedimentos técnicos, a qualquer pessoa construir uma página que a representa. Neste caso, não se pode mais falar em usuário passivo para o qual se cria e mantém um dado serviço, ou agregado de informação, porém em usuário participante, que organiza e comunica sua própria informação. (FREIRE, 2010)

A sociedade ao longo da sua história necessitou se adaptar às diversas transformações sociais provenientes da modernidade.

O mundo, com o passar do tempo, foi ganhando novos traços: a velocidade venceu a lentidão; o individualismo superou o altruísmo; o holismo ultrapassou o cartesianismo; o dinamismo subjugou o marasmo; a flexibilidade transpôs a rigidez; o planejamento domou a improvisação; a barbárie aniquilou o humanismo; o conhecimento almeja dominar a ignorância; a inteligência artificial persegue, a passos largos e obstinados, a inteligência natural; a máquina quer, a todo custo, substituir o homem...(PIMENTA, 2014, p.34)

Esse novo cenário tecnológico que tem mudado a nossa forma de agir, que tem alterado o modo como realizamos as atividades diárias, nada mais é que a consolidação da cibercultura, a cibercultura "se impõe como matriz de sentido contemporânea, na medida que pauta e é pautada por temas da sociedade e ao se imiscuir nas práticas cotidianas, torna-se objeto dos produtos culturais" (MONTARDO, 2005). Ela é "fruto de novas formas de relação 
social" (LEMOS, 2007, p. 257). A necessidade de adaptar-se é proveniente desse cenário inovador, no qual os produtos tecnológicos já são criados com prazos de validade para sua obsolescência, essa característica de inovar, tentar mudar, é uma algo indissociável do ser humano, seja motivado por algum interesse pessoal, profissional, ou simplesmente por mera curiosidade, vontade de inovar, modernizar. Para Berman (1986, p.15) "ser moderno é encontrar-se em um ambiente que promete aventura, poder, alegria, crescimento, autotransformação, e transformação das coisas em redor."

Diante do rápido processo de modernização tecnológica que vem ocorrendo desde as últimas décadas e que tem levado as pessoas a mudarem seus hábitos e costumes, é interessante tentar identificar as características e tendências dos comportamentos sociais que vem se estabelecendo nesse novo cenário, diferenciar o estágio atual em relação ao estágio anterior, os canais pelos quais as pessoas acessam a informação tem se modificado devido ao advento das TDICs, bem como a popularização da internet nos dias atuais. Segundo Oliveira (2004) a informatização está promovendo:

A conexão mundial através de uma rede de comunicação, da qual fazem parte, o computador, o telefone, o fax, a internet, a intranet, e extranet, o email, entre outros, possibilitando maior interação com o planeta sob os vários pontos de vista: econômico, político, social, geográfico, cultural e ecológico. (OLIVEIRA, 2004)

Os profissionais que atuam em bibliotecas precisam estar atentos às mudanças no comportamento das pessoas, saber o que mudou diante da oferta desses novos aparatos tecnológicos que dispõe de tanta comodidade e facilidade no acesso à informação, para que se adeque aos novos hábitos da comunidade, uma vez que a biblioteca tem um relevante papel no desenvolvimento da sociedade da informação, devido ao seu papel de detentora informacional, oferecendo acesso à informações gerais e utilitárias importantes para a sociedade.

Diante do exposto, o artigo busca refletir sobre as transformações sociais e culturais do processo de consolidação da cibercultura decorrentes da inserção e popularização das TDICs na sociedade, bem como as contribuições dessas tecnologias como canal mediador para a troca de informações entre as bibliotecas e os usuários. Nesta perspectiva, o estudo objetiva ponderar sobre as perspectivas e transformações nas formas de se relacionar que ferramentas como as mídias sociais tem possibilitado por meio da internet, buscando destacar aspectos essenciais que envolvem a biblioteca universitária e o usuário da informação.

\section{PERSPECTIVAS E TRANSFORMAÇÕES DOS USUÁRIOS DA INFORMAÇÃO}


Diante dos avanços tecnológicos e da expansão expressiva do uso da internet pela sociedade, é cada vez mais notável as mudanças nos hábitos de busca informacional, o uso dos recursos tecnológicos tem se tornado cada vez mais assíduo e indispensável na vida das pessoas, com isso, se torna cada vez mais aparente a opção pelas informações que se encontram em fontes virtuais na internet, sejam elas disseminadas por canais formais ou informais, em detrimento das fontes impressas que se encontram em espaços físicos tradicionais como as bibliotecas. As TDICs tem sido utilizadas em diferentes atividades no que se refere à manipulação informacional, como a organização, a pesquisa, a armazenagem, a disseminação e a recuperação da informação.

As tecnologias não tem apenas alterado o comportamento das pessoas, ela vem influenciando também, o modo de vida social no que se refere às relações humanas e demais aspectos desse contexto. Chartier (1994) tem nos afirmado que "o livro já não exerce o poder de que dispôs antigamente, já não é o mestre de nossos raciocínios e sentimentos em face dos novos meios de informação e comunicação de que doravante dispomos", pois, cada vez mais, a informação está sendo disponibilizada na forma eletrônica.

O computador [...] possibilita a produção, o armazenamento e a distribuição da informação provinda de outras hipermídias híbridas por sua capacidade de traduzi-las, absorvê-las, descrevê-las e de ser meio para recuperação, construindo uma linguagem tecnológica universal. (JORENTE, 2012)

Na sociedade contemporânea caracterizada pela influência das TDICs, os dispositivos eletrônicos conectados à internet torna-se um importante aliado no momento da disseminação informacional e a internet um canal eficiente em relação à sua potencialidade de proporcionar o acesso à essas informações. Lima (2011) nos assevera que "a utilização e o desenvolvimento das TDICs proporcionam a contínua expansão do ciberespaço, o que por sua vez estimula o surgimento de novas formas de interação e novos hábitos sociais."

Esses novos comportamentos tem se mostrado como um caminho que podemos dizer irreversível e tem modificado modelos outrora vigentes.

Para a sociedade, de forma geral, as tecnologias modificam e se modificam em si mesmas pela ação transformadora do homem, por meio delas e, no contexto mais atual, representam o suporte para uma revolução digital e, consequentemente para novas modificações nas relações humanas.(NEVES, 2010)

É isso que temos visto se consolidando cada dia mais em nossa sociedade, as mudanças de comportamentos sociais acompanhando a evolução tecnológica. Como assevera Felipe (2012) "as TIC...promovem mudanças impactantes sobre a cultura dos indivíduos, reorientando os aspectos sociais, econômicos, políticos e científicos da sociedade dessa época." 
Desse modo, a forma como as pessoas buscam informação tem se modificado, as TDICs permitem que os indivíduos possam acessar informações de forma rápida independente de sua localização geográfica, permite também a troca de informações com outras pessoas que compartilham de uma mesmo interesse em qualquer hora ou lugar, esse é um dos fatores que tem atraído as pessoas a se manterem atualizadas por meio dos canais virtuais e com isso tem afetado o comportamento dos usuários da informação.

Tomaél (2008) reforça a importância que a internet vem exercendo no cotidiano da sociedade, afirmando que uma parte significativa dos principais recursos, antes disponíveis apenas em bibliotecas, pode ser acessado hoje de forma on-line na internet onde as máquinas de busca procuram respostas para praticamente qualquer consulta na rede. Dessa forma, 0 que antes só era possível em suportes impressos, hoje já se pode encontrar em meio digital facilitando a vida das pessoas.

A internet e suas facilidades no momento do acesso e aquisição de conhecimento vem se destacando quando o assunto são os suportes físicos, como nos diz Jorente (2012) quando pontua como exemplo que "a enciclopédia digital tem acessos mensais de mais de 388 milhões de pessoas que procuram um número dinâmico, portanto, de atualização diária, de mais de 16 milhões de artigos em mais de 260 línguas." Vemos com isso o grande volume de pessoas em busca de atualizar-se de forma rápida e acessível, forma essa que a internet e as mídias digitais proporcionam.

Essa realidade tem contribuído para que as bibliotecas contemporâneas desenvolvam novas formas de se relacionar com os seu público-alvo, por meio desses canais infocomunicacionais, ampliando e gerando novas possibilidades de estreitar os laços com seus usuários no momento de disseminar as informações e apresentar seus produtos e serviços informacionais.

Os bibliotecários precisam estar consciente de que com todo esse aparato tecnológico que nos é disponibilizado na contemporaneidade, a relação entre biblioteca e usuário precisa ir além das barreiras físicas, precisa estar pautada nesse novo cenário comunicacional com o uso das TDICs, tornando a biblioteca mais atraente e indispensável no momento da busca pela informação, aliando-se às mídias para tornar o usuário atualizado de forma autônoma e remota, sem precisar que este fique restrito ao atendimento presencial.

Esse novo cenário de mudanças tão rápidas possibilita às bibliotecas refletirem acerca dos modelos de acesso à informação até agora vigentes e os novos modelos que possam surgir, englobando "uma nova visão da práxis, incorporando novos temas prioritários, novas técnicas e métodos, novas hipóteses e teorias, num ciclo contínuo e permanente, e mais do que isto, inesgotável" (TARGINO, 2010). 
Repensar sua práticas, priorizando as novas formas de se relacionar contemporaneamente e utilizando as tecnologias info-comunicacionais ao seu favor, a biblioteca terá um leque de possibilidades e formas de disponibilizar suas informações, promovendo a interação com os usuários que vivem conectados à internet em busca de informações rápidas e de fácil acesso, possibilitando para eles um acesso à informações de qualidade. Nessa perspectivas as bibliotecas podem fazer uso das mídias sociais, tendo em vista que elas apresentam um alto nível de eficácia quanto à utilização como canal de transferência de informação, ampliando, dessa forma, a satisfação dos usuários que independente de sua localização geográfica estarão sendo informados do mesmo modo que os usuários que buscam informações de forma presencial.

\section{AS BIBLIOTECAS UNIVERSITÁRIAS NO CENÁRIO DAS TECNOLOGIAS DIGITAIS DE INFORMAÇÃO E COMUNICAÇÃO (TDICS)}

A atuação da biblioteca universitária está diretamente vinculada ao meio ambiente acadêmico no qual ela está inserida, assumindo o papel de mediadora da informação, e tem como objetivo maior o desenvolvimento educacional. De acordo com Fujita (2005, p.100), as funções da biblioteca universitária são:

- Armazenagem do conhecimento: desenvolvimento de coleções, memória da produção científica e tecnológica, preservação e conservação;

- Organização do conhecimento: qualidade de tratamento temático e descritivo que favoreça o intercâmbio de registros entre bibliotecas e sua recuperação;

- Acesso ao conhecimento: a exigência de informação transcende o valor, o lugar e a forma e necessita de acesso. Por isso devemos pensar não só em fornecer a informação, mas possibilitar o acesso simultâneo de todos.

A biblioteca universitária convive, de um lado com uma coleção de documentos impressos, e de outro com o desenvolvimento acelerado de uma coleção de documentos com novos formatos presentes na internet, tendo em vista que ela está inserida no processo de socialização do conhecimento e como tal devem acompanhar os processos evolutivos não apenas tecnológico como também social e econômico. Fazendo uso das ferramentas tecnológicas para automatizar suas técnicas de gerenciamento da informação como é o caso dos processos diários de coleta, registro, armazenamento, recuperação e disseminação dessas informações. 
Apesar de haver consciência da grande importância da biblioteca nas universidades, a mesma ainda sofre com a falta de recursos financeiros advindos do Governo e, como consequência deste fato, provoca o sucateamento dos equipamentos, que se encontram ultrapassados, dificultando essa transição do universo que é considerado tradicional para o universo virtual. Mesmo assim, com todas as dificuldades, essas bibliotecas dão a sua contribuição para o desenvolvimento do ensino, da pesquisa e da extensão, pois esses são os objetos da missão universitária.

Se a biblioteca é importante para o ensino em geral, no ensino superior seu papel é proeminente em virtude do valor da própria universidade, pois nenhuma outra instituição ultrapassa em magnitude a contribuição universitária, a qual torna possível e formidável o avanço tecnológico e científico que se registra atualmente em todos os campos do conhecimento. (FERREIRA, 1980, p.7)

À medida que a produção intelectual vai aumentando, a biblioteca precisa estar atenta para disponibilizar essas informações aos seus usuários de forma mais acessível. Tal ação exige da biblioteca em um futuro muito próximo, total imersão nesse cenário tecnológico que a cada dia se consolida na sociedade e que cada vez mais presenciamos a crescente utilização das TDICs em todas as áreas da vida das pessoas. Essas tecnologias podem ser de grande proveito para a biblioteca no quesito de agilidade no momento da disseminação da informação, como também na divulgação dos produtos e serviços informacionais, propiciando às atividades uma maior dinamicidade. Como nos afirma Ribeiro (2012) ao dizer que:

O usuário não deseja inovações radicais, as incrementais já satisfazem o desejo por mudança. As bibliotecas universitárias estão conscientes desta nova característica do mercado e por disponibilizarem mais serviços que produtos, se pautam nas TICs para inovar e consequentemente oferecer mais e melhores serviços principalmente os de informação, seu ponto chave, sem esquecer os outros como os de lazer e entretenimento (sim se pode encontrar os dois em bibliotecas) a exemplo dos serviços de ação cultural. (RIBEIRO, 2012)

O avanço e a implementação das TDICs no ambiente da biblioteca, contribuem de forma eficaz na oferta de possibilidades inovadores de mediar a informação e de fazer chegar ao usuário de forma dinâmica informações relevantes e fidedignas. Esse novo cenário comunicacional propicia também novos desafios e novas formas de sociabilidade para as bibliotecas universitárias, decorrente das mudanças constantes e da variedade de recursos que podem ser utilizado para que os serviços sejam oferecidos da melhor forma possível aos usuários, como também para atender as mudanças provocadas pelos novos suportes 
tecnológicos de armazenagem, aumentando a responsabilidade da biblioteca dentro do ambiente em que está inserida e da sociedade como um todo.

Nessa perspectiva, as bibliotecas universitárias podem ampliar suas fronteiras com o uso das TDICs, estabelecendo novas ações comunicacionais baseadas nas tecnologias, adotando dessa forma, uma atitude mais pró-ativa que podem resultar em ganhos tanto para a biblioteca no sentido de rapidez e eficiência quanto para os usuários da informação que ganharão em poder acessar com a comodidade que as TDICs oferecem, informações relevantes e de credibilidade.

\section{TECNOLOGIAS DIGITAIS DE INFORMAÇÃO E COMUNICAÇÃO: O PAPEL DAS MÍDIAS SOCIAIS NA DISSEMINAÇÃO DA INFORMAÇÃO EM BIBLIOTECAS}

Atualmente estamos vivendo um período de mudanças constantes nas formas de se relacionar socialmente, as TDICs avançam de forma muita rápida e consequentemente o indivíduo vai se adaptando aos novos modelos comunicacionais que nos são apresentados. Esse novo cenário nos mostra uma nova forma de convivência que pode ser denominada de organização em rede, essa organização se dá por meio das pessoas com o auxílio das tecnologias que se organizam para manterem laços comunicacionais independentes de sua localização geográfica. De acordo com Castells (2006) "o avanço tecnológico proporcionou um aumento exponencial do efeito de rede, modelando a sociedade atual, na qual se insere a sociedade da informação e do conhecimento". Por isso o autor chama a sociedade contemporânea de sociedade em rede, tecendo crítica ao termo "sociedade da informação", já que segundo o autor, a informação sempre foi importante para o desenvolvimento social. Para Castells a estrutura social/ informacional em rede, baseada nas tecnologias digitais de informação e comunicação é que molda e caracteriza a sociedade atual, por isso o autor destaca a ideia de rede.

A forte influencia que as TDICs tem exercido nas pessoas, tem solidificado uma mudança perceptível e podemos dizer irreversível em relação aos modos de interação. As mídias sociais tem exercido o papel de suportes sociais que tem auxiliado de forma intensa essas atividades sociais no contexto virtual, o qual também pode ser denominado de ciberespaço. Castells (2008) nos assegura que o ciberespaço é a sociedade em rede, aldeia global, um cenário dinâmico baseado no fluxo e troca de informação, capital e cultura. Desse modo, as mídias sociais tem auxiliado a formação das redes sociais na internet, essas redes são constituídas por meio das pessoas que alimentam um fluxo de trocas informacionais, fazendo o papel de disseminadores virtuais de informação. Segundo Levy 
O surgimento das mídias sociais como o Facebok, o twitter, os blogs, tem propiciado uma nova organização social no que se refere às formas de se relacionar e disseminar informações. Essas ferramentas estão dispostas na internet e funcionam como canais de comunicação que podem ser utilizados pelas bibliotecas para estabelecer relacionamento com seus usuários, elas podem funcionar como um mecanismo de interação eficaz além de servir de canal transmissor para a disseminação de informações relevantes.

Podemos visualizar abaixo algumas funcionalidades das ferramentas de comunicação quando aplicadas em bibliotecas:

\section{Fecebook:}

- Compartilhamento de informações, por meio de textos, fotos ou vídeos sobre atividades na biblioteca;

- Compartilhamento de novas obras recebida pela biblioteca;

- Pode servir de ferramenta de chat entre a biblioteca e o usuário;

- Publicação de listas de reserva de obras, entre outras coisas.

\section{Twitter:}

- Divulgação de eventos que está para acontecer na biblioteca;

- Divulgar informações sobre lançamento de livros ou cursos a serem ministrados no ambiente da biblioteca;

- Receber dos usuários dicas de livros para compras, entre outras informações.

\section{Blog:}

- Propicia uma abertura maior para discussão entre a biblioteca e o usuário sobre assuntos relativos à biblioteca;

- Disponibilizar dicas sobre preservação de obras, dicas de pesquisas em bases de dados relevantes;

- Disponibilizar vídeos com apresentações dos produtos e serviços que a biblioteca dispõe, entre outras coisas.

É importante ressaltar que essas ferramentas de comunicação podem trazer informações relevantes que precisam ser descobertas/filtradas pelo profissional da informação e posteriormente organizadas sistematicamente em um novo espaço de comunicação. Isso possibilita a oferta de um novo serviço/produto de informação disponibilizado pela biblioteca. Um novo serviço que surge a partir de prospecção informacional feita a partir das ferramentas de comunicação supra citadas. 
Diante das variedades das ferramentas comunicacionais e de suas funcionalidades, torna-se necessário que a biblioteca analise e avalie o potencial dessas tecnologias, estabelecendo técnicas para implementar e gerir a prestação de serviços por meios dessas ferramentas, selecionando as que auxiliarão de forma eficiente na mediação da informação, oferecendo aos usuários que buscam cada vez mais se informar com mais comodidade e agilidade por meio das TDICs uma independência na momento da aquisição de conhecimento, independência essa, tão almejadas por esses usuários "conectados".

\section{ALGUMAS CONSIDERAÇÕES}

O artigo faz um convite à reflexão a respeito das transformações nas formas de se relacionar entre a biblioteca e o usuário, relações que estão cada vez mais mediadas pelas TDICs no contexto sociocultural da cibercultura, buscando apresentar um melhor entendimento do papel das tecnologias e da contribuição que ela pode dar para as bibliotecas.

A emergência de novas formas de relacionamento advindas do estabelecimento da cibercultura, por meio das ferramentas digitais de comunicação disponibilizadas na internet mediam os processos de trocas informacionais, modificando o comportamento da sociedade em relação aos canais pelos quais acessam a informação. As TDICs criam e ampliam novas formas de explorar e experimentar a vasta quantidade de informações disponibilizadas na internet. Essas mudanças tem reforçado ainda mais a necessidade de inovação no perfil do profissional da informação.

É necessário que o profissional da informação inove, trazendo para a biblioteca novas formas de se relacionar com o usuário, modernize e incorpore alterações que atendam ao atual cenário de cultura virtual que se consolida cada vez mais em nosso sociedade, frutos das transformações provenientes da contemporaneidade.

A atual atual conjuntura sociocultural no que se refere às formas de se relacionar, exige do profissional da informação o domínio de ferramentas que funciona como canal mediador de comunicação e informação presentes no ciberespaço, exige que ele esteja constantemente se adaptando ao novo, às novas forma de comunicação, à dinamicidade das ferramentas que mediam esse processo comunicacional e à maneira de se relacionar de forma virtual.

A questão é que as TDICs, mais precisamente as ferramentas de comunicação virtual ,revolucionaram e ampliaram as formas de se relacionar entre a biblioteca e seu público-alvo, estabelecendo mudanças nas formas de disseminar, trocar e explorar informações que levam a 
biblioteca a desempenhar um papel central na sociedade contemporânea, qual seja, o de facilitar, através do uso intensivo das TDICs, a transformação de informação em conhecimento.

\section{Referências}

ARRUDA, Byanka da Silva. Transformações culturais na sociedade da informação. Biblioteca On-line de Ciências da Comunicação. 2011. Disponível em: $<$ http://www.bocc.ubi.pt/pag/arruda-byanka-transformacoes-culturais-na-sociedade-dainformacao.pdf> Acesso em: 28 jun. 2014.

BERMAN, M. Tudo que é sólido se desmancha no ar: a aventura da modernidade. São Paulo: Companhia das Letras, 1986.

CASTELLS, M.; CARDOSO, G. (org.). A sociedade em rede: do conhecimento à ação política. Lisboa: Imprensa Nacional:Casa da Moeda, 2006.

CASTELLS, M. A sociedade em rede. 11. ed. São Paulo: Paz e Terra, 2008.

CHARTIER, Roger. Do códice ao monitor: a trajetória do livro. Estudos Avançados, IEA/USP, v. 8, n. 21. p. $185-199,1994$.

FELIPE, André Anderson Cavalcante. reflexões sobre as mudanças sociais motivadas pelo desenvolvimento tecnológico: a necessidade de instituir uma reflexão ética na utilização das tecnologias da informação e comunicação (tic). In: Biblionline, João Pessoa, v.8, n.2, p.16-26, 2012.

FERREIRA, Lusimar Silva. Bibliotecas universitárias brasileiras: análise de estruturas centralizadas e descentralizadas. São Paulo: Pioneira, 1980.

FREIRE, G. H. A. Redes virtuais de aprendizagem na sociedade e na pesquisa. Enc. Bibli: R. Eletr. Bibliotecon., Florianópolis, n. 25, 10 sem.2008.

FUJITA, Mariângela S. L. Aspectos evolutivos das Bibliotecas Universitárias em ambiente digital na perspectiva da rede de Bibliotecas da UNESP. In: Informação \& Sociedade: estudos, João Pessoa, v. 15, n. 2, p. 97-112, jul./dez. 2005

JORENTE, Maria José Vincentini. Impacto das tecnologias de informação e comunicação: cultura digital e mudanças sócio-culturais. Informação \& Sociedade: Estudos, João Pessoa, v.22, n.1, p.13-25, jan./abr. 2012.

LEMOS, A. Cibercultura: tecnologia e vida social na cultura contemporânea. Porto Alegre: Sulina, 2007.

LÉVY, Pierre. Cibercultura. Tradução de Carlos Irineu Costa. São Paulo: Editora 34, 1999. 
LIMA, Márcio Roberto de, LIMA, Eduardo Henrique de Matos, SILVA, Eloiza Cristina. Reflexos da Cibercultura: a democratização do acesso à memória histórica documental. Biblioteca Online de Ciências da Comunicação. 2011. Disponível em: <http://www.bocc.ubi.pt/pag/limalima-silva-reflexos-da-cibercultura.pdf>. Acesso em: 28 jun. 2014.

MONTARDO, Sandra Portella. Comunicação como forma social: proposta de interseçao entre a comunicação e a cibercultura. Biblioteca On-line de Ciências da Comunicação. 2005. Disponível em: <http://www.bocc.ubi.pt/pag/montardo-sandra-comunicacao-formasocial.pdf>. Acesso em: 28 jun. 2014.

NEVES, B. C. Pontos de inclusão digital baianos: uma abordagem cognitiva baseada na convergência de recursos e na mediação. 2010. 210 f. Dissertação (Mestrado em Ciência da Informação) - UFBA, Salvador, 2010.

OLIVEIRA, J. F. Sistemas de Informação versus Tecnologia da Informação. São Paulo: Érica, 2004.

PIMENTA, Márcia Teresa da Rocha. A política de inserção do Brasil na "Sociedade da Informação": uma avaliação política do Programa Sociedade da Informação (SOCINFO). 2014. 222f. Tese (Doutorado em Políticas Públicas) Universidade Federal do Maranhão. São Luís, 2014.

RIBEIRO, Rejane M. R. A tecnologia da informação e comunicação (TIC): fator condicionante da inovação em bibliotecas universitárias. Revista Digital de Biblioteconomia e Ciência da Informação, Campinas, v.9, n.2, p.41-48, jan./jun. 2012.

TARGINO, M. G. A. A biblioteca do século XXI: novos paradigmas ou meras expectativas? Informação \& Sociedade: Estudos, João Pessoa, v.20, n.1, p.39-48, jan./abr. 2010.

TOMAÉL, Maria Inês (Org.). Fontes de informação na internet. Londrina: EDUEL, 2008. 184 p. 